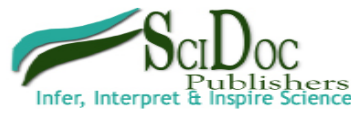

International Journal of Stem Cell Research and Transplantation (1JST)

ISSN: 2328-3548

\title{
Mass Production of Stem Cell-Derived Progeny in Bioreactors
}

Li $\mathrm{Y}^{*}$, Sart $\mathrm{S}^{1}$, Agathos $\mathrm{SN}^{2}$

Editorial

${ }^{1 *}$ Department of Chemical and Biomedical Engineering, FAMU-FSU College of Engineering, Florida State University, 525 Pottsdamer St, Tallahassee, Florida, USA.

2 Université Catholique de Louvain/Institut des Sciences de La Vie, Unit of Bioengineering, Place Croix du Sud 2/19, 1348 Louvain-la-Neuve, Belgium.

\section{*Corresponding Author:}

Yan Li,

Department of Chemical and Biomedical Engineering, FAMU-FSU College of Engineering, Florida State University,

2525 Pottsdamer St, Tallahassee, Florida, USA.

Tel: 850-410-6320; Fax: 850-410-6150

E-mail: yli@eng.fsu.edu

Received: April 26, 2013

Published: May 23, 2013

Citation: Li Y, Sart S, Agathos SN. (2013). Mass Production of Stem Cell-Derived Progeny in Bioreactors, Int J Stem Cell Res Transplant, 01(3e), 01-02. doi: http://dx.doi.org/10.19070/2328-3548-130003e

Copyright: Li $\mathbf{Y}^{\odot}$ 2013. This is an open-access article distributed under the terms of the Creative Commons Attribution License, which permits unrestricted use, distribution and reproduction in any medium, provided the original author and source are credited.

Stem cells, including mesenchymal stem cells (MSCs) and pluripotent stem cells (PSCs), have shown great potential for various biomedical applications including drug discovery, disease modeling, and tissue engineering [1-4]. Especially, the discovery of induced pluripotent stem cells (iPSCs) with similar characteristics to embryonic stem cells (ESCs) opens a new era for stem cell research and transplantations [5]. Bioprocess engineering provides a platform to generate a controlled microenvironment that could potentially recreate a stem cell niche in view of promoting stem cell proliferation or lineage-specific differentiation.

A bioprocess engineering strategy, through the use of well-controlled bioreactors, aims at achieving the large scale production of stem cells, improving their biological properties, and ensuring the safety in clinical use following the guidelines of current Good Manufacturing Practices (cGMP) [6,7]. For instance, microcarrierbased bioreactors enable easy scale up for anchorage-dependent stem cells, demonstrating high reproducibility on regulation of cellular behaviors together with the compliance under cGMP. Microcarriershave been investigated for stem cell expansion and differentiation in stirred tank bioreactors and rotating wall bioreactors, including MSCs and PSCs as well as differentiated tissuespecific cells (e.g. osteoblasts, neurons, cardiomyocytes etc.)[8-13]. As for custom-made biomaterials, the accurate biochemical and biomechanical characterization of the microcarriers (i.e. surface composition and modulus) will help to fully exploit their potential in regulating the stem cell fate decision. For instance, it has been shown that microcarrier surface properties modulated MSC adhesion and cytoskeleton, which in turn regulated chondrogenic differentiation [14]. Another suspension culture organization in bioreactors is the self-assembled aggregates, which has been shown recently for both PSCs and MSCs [6,15]. This 3-D organization promotes cell-cell adhesion and the secretion of growth factors, allowing large scale expansion as well as enhanced therapeutic potential. Most importantly, suspension culture in bioreactors with either microcarriers or aggregates enables the process integration of iPSC reprogramming, stem cell self-re newal, and the lineagespecific differentiation $[16,17]$.

Bioreactors promote efficient mass transfer and enable the control of nutrient feeding mode to regulate cell metabolism [18]. For instance, glucose and oxygen metabolisms play a key role in MSC and PSC expansion and differentiation [19]. The efficient expansion of stem cells relies on glycolysis, while during differentiation stem cells generally switch their metabolism to oxidative phosphorylation (e.g. cardiomyocytes derived from PSCs) [20-22]. As a consequence, the requirements for glucose and oxygen vary upon different phases of stem cell production. Accurate understanding of stem cell metabolism is critical for the rational design of culture parameters such as feeding regime in bioreactors for efficient integrated expansion and differentiation at large scale. In the same vein, the generation of gradients of cytokines and growth factors in the bioreactors enables the design of adequate niches to promote efficient stem cell differentiation, as shown in mesodermal lineage commitment and the regulation of ESC self-renewal $[23,24]$.

Besides the improved mass transfer and diffusion, bioreactors also enable the control of stem cells' exposure to mechanical forces, providing additional signaling for differentiation or sustainment of the stem cell properties [25]. For instance, the activation of Wnt signaling for MSC osteogenic differentiation or the sustained self-renewal of ESCs and alternatively their commitment is regulated by mechanical force [26-28]. The mechanical stress has also been shown to induce autocrine/paracrine signaling of transforming growth factor (TGF) $\beta$ superfamily and activate $\mathrm{Smad} 2 / 3$ pathway to suppress spontaneous differentiation of human PSCs [29,30]. These findings underscore the importance of reciprocal interactions of autocrine/paracrine signals and mechanical force in 3-D cellular organizations during stem cell self-renewal and lineage commitment.

Together, this editorial indicates that rational bioprocess engineering strategies applied to stem cell cultivation in bioreactors constitutes the ideal way to monitor the microenvironment of stem cells. Accurate microcarrier characterization, the controlled feeding mode, and the magnitude of applied mechanical force should lead to the improvement in stem cell expansion and differentiation ex vivo that ultimately meet the clinical demand with the large number of cells as well as the safety considerations. 


\section{References}

[1]. L.B. Hazeltine, J.A. Selekman, S.P. Palecek, Engineering the human pluripotent stem cell microenvironment to direct cell fate, Biotechnol Adv, In Press (2013), doi: 10.1016/j.biotechadv.2013.03.002.

[2]. 2. A. Chen, S. Reuveny, S. Oh, Application of Human mesenchymal and pluripotent stem cell microcarrier cultures in cellular therapy: achievements and future direction, Biotechnol Adv, In press (2013), doi: 10.1016/j. biotechadv.2013.03.006.

[3]. 3. Y. Li, A. Gautam, J. Yang, L. Qiu, Z. Melkoumian, J. Weber, L. Telukuntla, R. Srivastava, E.M. Whiteley, R. Brandenberger, Differentiation of oligodendrocyte progenitor cells from human embryonic stem cells on vitronectin-derived synthetic peptide acrylate surface, Stem Cells Dev, 22 (2013) 1497-1505.

[4]. 4. Y. Li, T. Ma, Stem cell-based dendritic cell vaccine development: A review with emphasis on lung cancer treatment, J Hemato Malig, 1 (2011) $35-48$.

[5]. 5. S.M. Wu, K. Hochedlinger, Harnessing the potential of induced pluripotent stem cells for regenerative medicine, Nat Cell Biol, 13 (2011) 497-505.

[6]. 6. M. Serra, C. Brito, C. Correia, P.M. Alves, Process engineering of human pluripotent stem cells for clinical application, Trends Biotechnol, 30 (2012) 350-359.

[7]. 7. N. Liu, R. Zang, S.T. Yang, Y. Li, Stem cell engineering in bioreactors for large scale bioprocessing, Eng Life Sci, In press (2013).

[8]. 8. R. Alfred, J.T. Taiani, R.J. Krawetz, A. Yamashita, D.E. Rancourt, M.S. Kallos, Large-scale production of murine embryonic stem cell-derived osteoblasts and chondrocytes on microcarriers in serum-free media, Biomaterials, 32 (2011) 6006-6016.

[9]. 9. S. Sart, Y.J. Schneider, S.N. Agathos, Ear mesenchymal stem cells: an efficient adult multipotent cell population fit for rapid and scalable expansion, J Biotechnol, 139 (2009) 291-299.

[10]. 10. A.K. Chen, X. Chen, A.B. Choo, S. Reuveny, S.K. Oh, Critical microcarrier properties affecting the expansion of undifferentiated human embryonic stem cells, Stem Cell Res, 7 (2011) 97-111.

[11]. 11. J. Bardy, A. Chen, Y.M. Lim, S.M. Wu, S. Wei, W. Han, K.K. Chan, S. Reuveny, S. Oh, Microcarrier suspension cultures for high density expansion and differentiation of human pluripotent stem cells to neural progenitor cells, Tissue Eng Part C Methods, 19 (2013) 166-180.

[12]. 12. M. Lecina, S. Ting, A. Choo, S. Reuveny, S. Oh, Scalable platform for human embryonic stem cell differentiation to cardiomyocytes in suspended microcarrier cultures, Tissue Eng Part C Methods, 16 (2010) 1609-1619.

[13]. 13. L.T. Lock, E.S. Tzanakakis, Expansion and differentiation of human embryonic stem cells to endoderm progeny in a microcarrier stirred-suspension culture, Tissue Eng Part A, 15 (2009) 2051-2063.

[14]. 14. S. Sart, A. Errachid, Y.J. Schneider, S.N. Agathos, Modulation of mesenchymal stem cell actin organization on conventional microcarriers for proliferation and differentiation in stirred bioreactors, J Tissue Eng Regen Med, (2013) doi:10.1002/term.545.

[15]. 15. J.E. Frith, B. Thomson, P.G. Genever, Dynamic three-dimensional culture methods enhance mesenchymal stem cell properties and increase therapeutic potential, Tissue Eng Part C Methods, 16 (2010) 735-749.
[16]. 16. D.A. Fluri, P.D. Tonge, H. Song, R.P. Baptista, N. Shakiba, S. Shukla, G. Clarke, A. Nagy, P.W. Zandstra, Derivation, exYan Li, International Journal of Stem Cell Research and Transplantation 2013, 1:201 3 pansion and differentiation of induced pluripotent stem cells in continuous suspension cultures, Nat Methods, 9 (2012) 509-516.

[17]. 17. N. Liu, Y. Li, S.T. Yang, Microfibrous carriers for integrated expansion and neural differentiation of embryonic stem cells in suspension bioreactor, Biochem Eng J, 75 (2013) 55-63.

[18]. 18. P. Godara, C.D. McFarland, R.E. Nordon, Design of bioreactors for mesenchymal stem cell tissue engineering, J Chem Technol Biotechnol, 83 (2008) 408-420

[19]. 19. N.M. Vacanti, C.M. Metallo, Exploring metabolic pathways that contribute to the stem cell phenotype, Biochim Biophys Acta, 1830 (2013) 2361-2369.

[20]. 20. G. Pattappa, H.K. Heywood, J.D. de Bruijn, D.A. Lee, The metabolism of human mesenchymal stem cells during proliferation and differentiation, J Cell Physiol, 226 (2011) 2562-2570.

[21]. 21. J. Zhang, E. Nuebel, D.R. Wisidagama, K. Setoguchi, J.S. Hong, C.M. Van Horn, S.S. Imam, L. Vergnes, C.S. Malone, C.M. Koehler, M.A. Teitell, Measuring energy metabolism in cultured cells, including human pluripotent stem cells and differentiated cells, Nat Protoc, 7 (2012) 10681085.

[22]. 22. S. Chung, P.P. Dzeja, R.S. Faustino, C. Perez-Terzic, A. Behfar, A. Terzic, Mitochondrial oxidative metabolism is required for the cardiac differentiation of stem cells, Nat Clin Pract Cardiovasc Med, 4 Suppl 1 (2007) S60-67.

[23]. 23. E. Cimetta, D. Sirabella, K. Yeager, K. Davidson, J. Simon, R.T. Moon, G. Vunjak-Novakovic, Microfluidic bioreactor for dynamic regulation of early mesodermal commitment in human pluripotent stem cells, Lab Chip, 13 (2013) 355-364.

[24]. 24. L.M. Przybyla, J. Voldman, Attenuation of extrinsic signaling reveals the importance of matrix remodeling on maintenance of embryonic stem cell self-renewal, Proc Natl Acad Sci U S A, 109 (2012) 835-840.

[25]. 25. D. Li, T. Tang, J. Lu, K. Dai, Effects of flow shear stress and mass transport on the construction of a large-scale tissueengineered bone in a perfusion bioreactor, Tissue Eng Part A, 15 (2009) 2773-2783.

[26]. 26. E.J. Arnsdorf, P. Tummala, R.Y. Kwon, C.R. Jacobs, Mechanically induced osteogenic differentiation--the role of RhoA, ROCKII and cytoskeletal dynamics, J Cell Sci, 122 (2009) 546-553.

[27]. 27. E.J. Arnsdorf, P. Tummala, C.R. Jacobs, Non-canonical Wnt signaling and $\mathrm{N}$-cadherin related beta-catenin signaling play a role in mechanically induced osteogenic cell fate, PLoS One, 4 (2009) e 5388.

[28]. 28. D. Titmarsh, A. Hidalgo, J. Turner, E. Wolvetang, J. Cooper-White, Optimization of flowrate for expansion of human embryonic stem cells in perfusion microbioreactors, Biotechnol Bioeng, 108 (2011) 2894-2904

[29]. 29. S. Saha, L. Ji, J.J. de Pablo, S.P. Palecek, TGFbeta/Activin/ Nodal pathway in inhibition of human embryonic stem cell differentiation by mechanical strain, Biophys J, 94 (2008) 4123-4133.

[30]. 30. C.Y. Sargent, G.Y. Berguig, M.A. Kinney, L.A. Hiatt, R.L. Carpenedo, R.E. Berson, T.C. McDevitt, Hydrodynamic modulation of embryonic stem cell differentiation by rotary orbital suspension culture, Biotechnol Bioeng, 105 (2010) 611-626. 